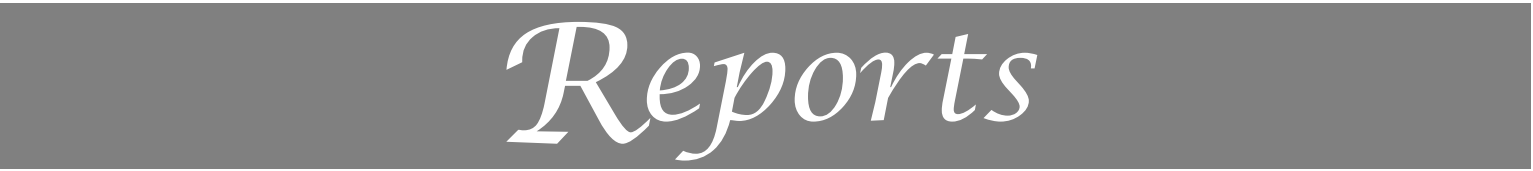

Ecology, 96(5), 2015, pp. 1159-1165

(c) 2015 by the Ecological Society of America

\title{
Demographic heterogeneity and the dynamics of open populations
}

\author{
Erik G. Noonburg, ${ }^{1,4}$ Adam Chen, ${ }^{1}$ Jeffrey S. Shima, ${ }^{2}$ and Stephen E. Swearer ${ }^{3}$ \\ ${ }^{1}$ Department of Biological Sciences, Florida Atlantic University, 3200 College Avenue, Davie, Florida 33314 USA \\ ${ }^{2}$ School of Biological Sciences, P.O. Box 600, Victoria University of Wellington, New Zealand \\ ${ }^{3}$ School of BioSciences, University of Melbourne, Melbourne, Victoria 3010 Australia
}

\begin{abstract}
Individuals vary in their phenotype and propensity for growth and survival, but the demographic consequences of this remain poorly understood. We extend previous theoretical work on benthic marine populations and formulate a new model to evaluate how demographic heterogeneity among newly settled reef fish affects population stability. We simulated settlement, growth, and mortality of a small reef fish, the common triplefin (Forsterygion lapillum) in an open "subpopulation" using a delay-differential equation model framework. We modeled demographic heterogeneity with a discrete number of "quality" types, motivated by our previous empirical observations: individuals were either "high quality" (immigrants from nearby subpopulations) or "low quality" (immigrants from distant subpopulations); in our model, quality influences how quickly individuals develop at a given competitor density. Our results demonstrate how demographic heterogeneity and juvenile competition interact to qualitatively alter the effects of settlement on population stability. Specifically, our model suggests that a mixture of quality types can stabilize the equilibrium even when equal settlement of either type alone would result in an unstable equilibrium. These results highlight the importance of among-individual variation in a metapopulation context, and suggest that in systems where dispersal influences individual quality, connectivity may serve to stabilize local populations.
\end{abstract}

Key words: connectivity; delay-differential equation; demographic heterogeneity; density dependence; Forsterygion lapillum; growth variation; open population; population regulation; recruitment.

\section{INTRODUCTION}

Many coastal marine organisms live in demographically open, spatially structured populations. Adults produce large numbers of poorly provisioned larvae that develop in open water and disperse among subpopulations. Most larvae ( $>99 \%$ ) fail to survive this initial stage (Houde 1989). Of the initial survivors, most die within days or weeks of their metamorphosis and settlement into adult habitats (Steele and Forrester 2002, Shima and Osenberg 2003, Doherty et al. 2004). The supply of new settlers can be further limited if the distances to neighboring subpopulations are great or if oceanographic conditions are unfavorable for larval exchange (Roughgarden et al. 1988, White and Caselle 2008, Pinsky et al. 2012). These regional influences on larval supply and the potential scarcity of settlers have

Manuscript received 10 August 2014; revised 26 November 2014; accepted 16 December 2014; final version received 8 January 2015. Corresponding Editor: B. E. Kendall

${ }^{4}$ E-mail: enoonbur@fau.edu led to intense debate over whether and how important local density-dependent processes such as competition and predation might be to the dynamics of subpopulations of many marine organisms (reviewed in Caley et al. 1996, Armsworth 2002, Hixon and Jones 2005, Hixon et al. 2012).

The debate has motivated a large body of theory to predict the consequences of different pre- and postrecruitment processes that might influence the dynamics of open populations (see, e.g., Armsworth 2002, Hastings and Botsford 2006, Burgess et al. 2014). A key assumption of this theory is that settlers arriving in a subpopulation are drawn from a homogeneous larval pool. Although multiple subpopulations might contribute to the larval pool, the origin and dispersal history of settlers are considered irrelevant to the local population dynamics. However, the assumption of a homogeneous larval pool is unsupported by a growing body of empirical evidence. For example, dispersal can be costly to individuals (Burgess et al. 2012), and stressful environmental conditions encountered during the dispersive phase can exert a strong influence on post- 
settlement demographic rates (e.g., Pechenik et al. 1998, Shima and Swearer 2009a, 2010, Marshall et al. 2010, Burgess and Marshall 2011). We therefore expect larvae that arrive from different natal subpopulations and experience different dispersal histories to exhibit substantial variation in subsequent performance. The effects of demographic heterogeneity on population growth rate, extinction risk, and density-dependent dynamics have been analyzed in models of closed populations (Melbourne and Hastings 2008, Kendall et al. 2011, Stover et al. 2011), but the consequences for dynamics of open populations have not been explored.

We address this question by incorporating demographic heterogeneity into a model of a single open population. We use our general framework to reexamine a classic prediction from models of open populations of space limited benthic species, for which theory has been particularly well developed (e.g., Roughgarden et al. 1985, Bence and Nisbet 1989, Nisbet and Bence 1989, Pascual and Caswell 1991, Inaba 2002, Artzy-Randrup et al. 2007). These models make the robust prediction that high larval settlement rate will destabilize the equilibrium adult density, resulting in population cycles. Bence and Nisbet (1989) argued that the instability is caused by the delay between larval settlement and growth to the adult space-occupying stage. For a population with sufficiently high settlement rate, the delay allows new recruits to overshoot the equilibrium before adult density is large enough to suppress further settlement. If well-connected subpopulations are likely to receive a steady supply of larvae, the tendency to cycle has important implications for metapopulation dynamics. For example, the instability may increase susceptibility to extinction at cycle minima and thereby alter the prediction that a few wellconnected subpopulations can increase metapopulation persistence (Gilarranz and Bascompte 2012).

Our model is motivated by the common triplefin (Forsterygion lapillum, see Plate 1), but the structure is a general representation of a subpopulation of small reef fish with larval dispersal and sedentary adults. Previous empirical work shows that individuals with different dispersal histories exhibit differences in pre-settlement growth that have carry-over effects on post-settlement growth and survival (Shima and Swearer 2009a, b, 2010; J. S. Shima and S. E. Swearer, unpublished data). Because the delay inherent in growth is critical to the predictions of related models (Bence and Nisbet 1989), we focus our model analysis on the interaction between demographic heterogeneity and density dependence in development rate. We demonstrate that heterogeneity in development rate, and the resulting variation in the delay between settlement and recruitment to the adult stage, can permit a stable equilibrium at any settlement rate. Furthermore, settlement of larvae with more than one value of quality can result in a stable equilibrium even when the same total settlement rate of any one larval quality type gives rise to an unstable equilibrium.
Model

The general model framework consists of a local population with two stages, adult and juvenile. We incorporate demographic heterogeneity by further subdividing juveniles into distinct quality types. Variation in quality is represented by differences in fixed demographic rates and differences in response to environmental conditions. For example, low-quality individuals could develop more slowly than high-quality individuals regardless of the environment, and/or development rate of low-quality individuals could decrease more rapidly with increasing competitor density. In the latter case, variation in quality determines the rate at which development decreases with deteriorating environmental conditions (i.e., increasing density of competitors).

Adult density at time $t$ is $N_{\mathrm{a}}(t)$, and the density of juvenile type $q$ is $N_{\mathrm{j} q}(t)$, where $q=1,2, \ldots, m$ is an arbitrary index of quality (see Table 1 for state variable/ parameter definitions and units). For example, if juvenile growth rate varies among settlers that arrive from different natal subpopulations, $q$ could indicate the identity of each subpopulation that supplies larvae to the focal subpopulation. The total settlement rate of larvae is $S(t)$, with units of density/time, and $p_{q}$ is the fraction of the total that are quality type $q$. Because we assume settlement rate does not depend on local population density, we do not track adult reproduction explicitly. The distinction between juveniles and adults simply represents a transition between life history stages based on, e.g., differences in foraging or territorial behavior. For our analyses, differences between adults and juveniles only affect density dependence.

We assume in our analyses that individual quality remains fixed throughout the juvenile stage. This represents irreversible phenotypic variation created during larval dispersal (e.g., Vigliola and Meekan 2002, McCormick and Hoey 2004), rather than, e.g., variation in condition that can be overcome by successful foraging after settlement. The transition between juvenile and adult stages occurs after a maturation delay $\tau_{q}(t)$ for type $q$ juveniles. All settlers of type $q$ that arrive at a given time mature simultaneously, i.e., there is no variation within a quality type. However, the time dependence in the maturation delay allows for the possibility of density dependence, such that larvae that arrive at different times may experience different fluctuations in conspecific density.

The rate of change of the adult population is the difference between total juvenile maturation rate and adult death rate

$$
\frac{d N_{\mathrm{a}}(t)}{d t}=\sum_{q=1}^{m} M_{q}(t)-\delta_{\mathrm{a}} N_{\mathrm{a}}(t)
$$

where $M_{q}(t)$ is the maturation rate for type $q$ juveniles (with units density/yr), and we assume adult mortality occurs at density independent rate $\delta_{\mathrm{a}}$. Similarly, the rate of change of type $q$ juveniles is 
TABLE 1. Model variables, parameters, and values for numerical results.

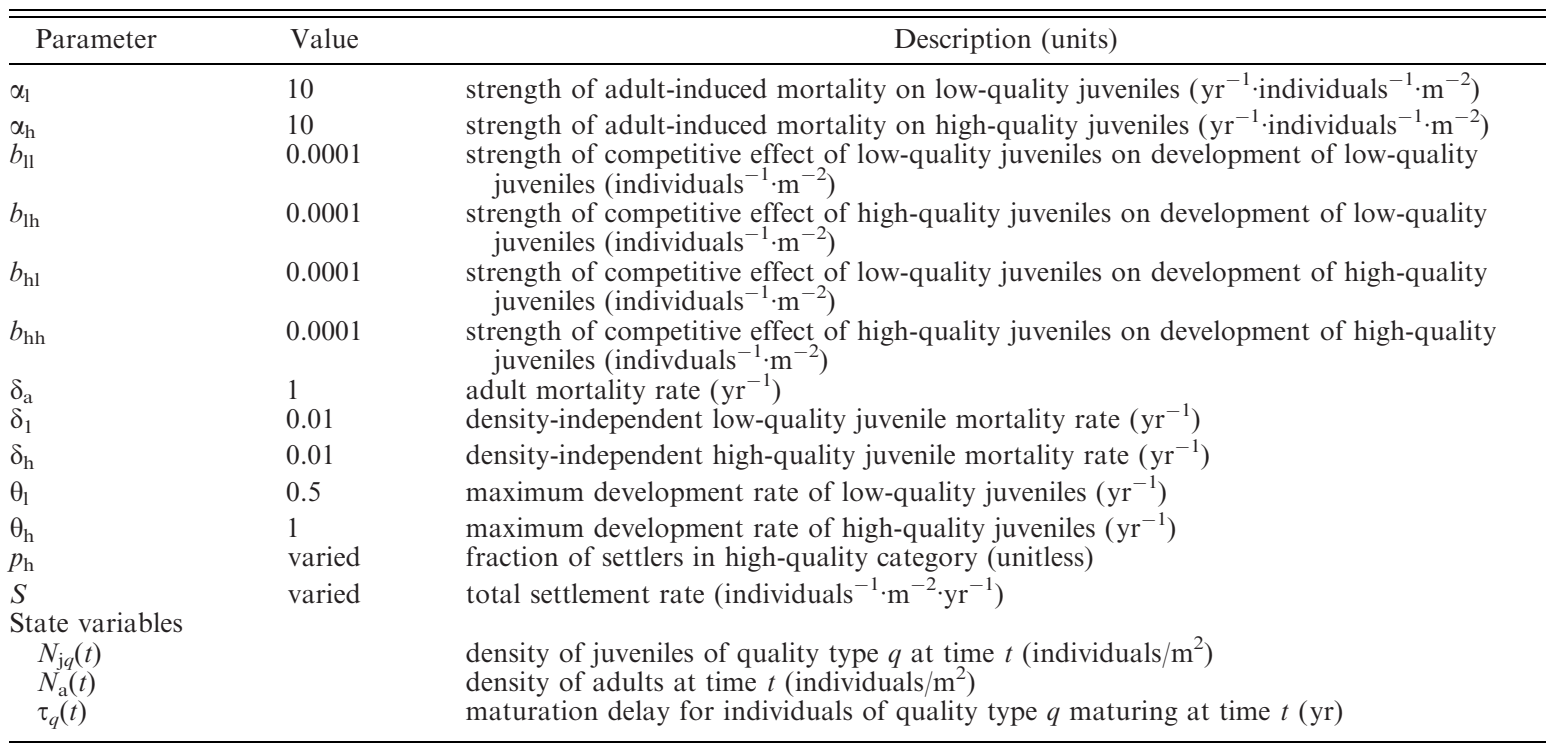

$$
\frac{d N_{\mathrm{j} q}(t)}{d t}=p_{q} S(t)-M_{q}(t)-\mu_{q}(t) N_{\mathrm{j} q}(t)
$$

where $\mu_{q}(t)$ is the juvenile mortality rate (with units of $\left.\mathrm{yr}^{-1}\right)$. The time dependence in juvenile mortality rate allows for density dependent interactions, as with the maturation delay. The maturation rate of type $q$ juveniles at time $t$ is equal to the settlement rate at $t-$ $\tau_{q}(t)$ multiplied by survival from settlement to maturation

$$
M_{q}(t)=p_{q} S\left(t-\tau_{q}(t)\right) \exp \left(-\int_{t-\tau_{q}(t)}^{t} \mu_{q}(x) d x\right) .
$$

In order to introduce density dependent feedback from adults to juvenile survival, we assume juvenile mortality rate is the sum of a density-independent term $\left(\delta_{\mathrm{j} q}\right)$ and a term that increases with adult density

$$
\mu_{q}(t)=\delta_{\mathrm{j} q}+\alpha_{q} N_{\mathrm{a}}(t)
$$

where $\alpha_{q}$ is the strength of adult-induced mortality, i.e., the slope of the linear relationship between adult density and mortality rate of quality type $q$ juveniles. The mortality caused by adults (second term in Eq. 4) could represent cannibalism from larger conspecifics as well as additional predation or starvation that results from adults chasing juveniles.

The maturation delay is defined as the time required for a settler to acquire sufficient resources to reach a threshold size or development level. We refer to this process as "development," and we denote development rate of type $q$ juveniles as $G_{q}(t)$, measured in development units/yr (see Eq. 6). We represent the effect of competition among juveniles with a phenomenological function for development rate (modified from Gurney and Nisbet 1998: 250-256)

$$
G_{q}(t)=\frac{\theta_{q}}{1+\sum_{i=1}^{m} b_{q i} N_{\mathrm{ji}}(t)}
$$

where the index $i$ in the summation is taken over all juvenile quality types. In this function, $\theta_{q}$ is the maximum development rate when no competitors are present (i.e., $N_{\mathrm{j} i}(t)=0$ for all $i$ ), and $b_{q i}$ represents the strength of the competitive effect of type $i$ juveniles on development of type $q$ juveniles. Eq. 5 implies that increasing density of juveniles in the environment reduces individual development rate; this could occur indirectly via depletion of food, or directly through aggression among individuals.

The maturation delay in Eq. 3 is specified implicitly as the time required for development to reach a threshold (e.g., growth to a critical size) by integrating development rate up to a constant, which we set to 1

$$
\int_{t-\tau_{q}}^{t} G_{q}(x) d x=1 .
$$

In other words, we measure development in units such that new settlers start at 0 and mature at 1 , and the time required to reach the maturation threshold increases with increasing competitor density (Eq. 5). Eq. 6 (with the development rate specified by Eq. 5) can be solved numerically to find $\tau_{q}$ as a function of time (see Gurney and Nisbet 1998, p252), which enters the population dynamics via settlement and survival in Eq. 3 . 

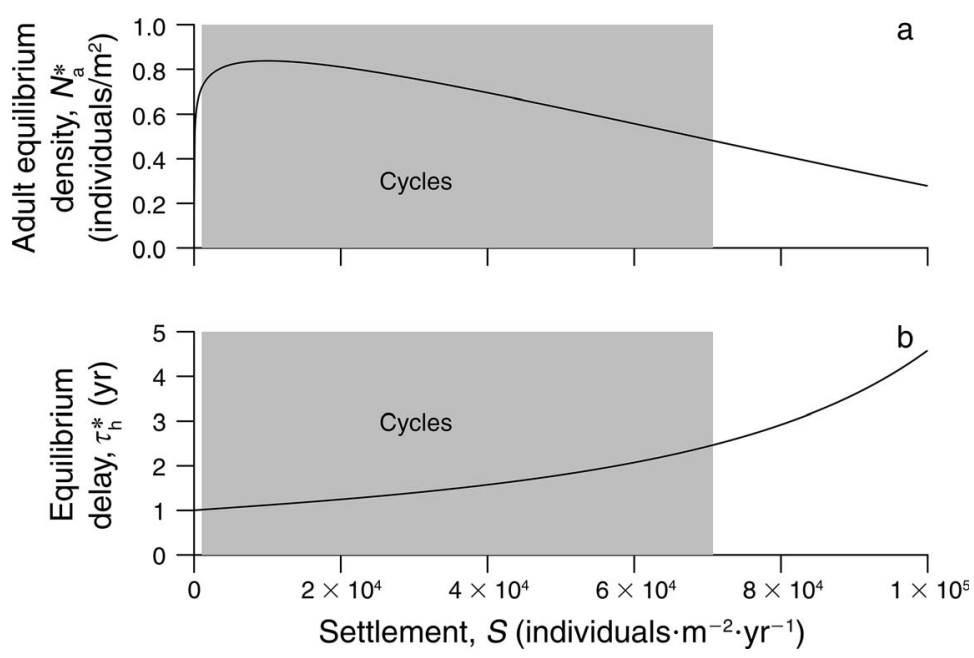

FIG. 1. Effects of settlement rate $(S)$ on (a) equilibrium adult density and (b) equilibrium maturation delay when there is no demographic heterogeneity $\left(p_{\mathrm{h}}=1\right)$. The model predicts an unstable point equilibrium with stable limit cycles for the range of $S$ indicated by shading. The equilibrium is stable for larger values of $S$ and for a narrow range of low $S$ (between zero and the shaded region). See Table 1 for parameter definitions.

In order to examine the effects of demographic heterogeneity on population dynamics, we use the simplest form of variation in quality, with only two classes representing high and low quality $(q=\mathrm{h}$ and 1 , respectively). We explore the scenario in which the two quality classes differ in their maximum development rate $\left(\theta_{q}\right.$; we consider other possibilities in the appendices). We assume larvae settle at a constant total rate, which we denote $S$. Settlement rate of high-quality larvae is $p_{\mathrm{h}} S$, where $p_{\mathrm{h}}$ is the fraction of settlers that are high quality. Settlement of low-quality larvae is therefore (1 $\left.p_{\mathrm{h}}\right) S$. In the context of our model system, high-quality settlers are larvae that have dispersed a relatively short distance, whereas low-quality settlers are larvae that arrive from more distant subpopulations and have experienced poor environmental conditions during dispersal (Shima and Swearer 2009a). In general, variation in $p_{\mathrm{h}}$ is intended as a simple representation of variation among subpopulations in the proportion of settlers derived from nearby vs. distant parent populations. We vary the total settlement rate $(S)$ independently of $p_{\mathrm{h}}$. For example, a subpopulation in which a large proportion of settlers arrive from nearby subpopulations (high $p_{\mathrm{h}}$ ) could be surrounded by highly productive subpopulations (high $S$ ) or by subpopulations with poor adult habitat (low $S$ ).

Because the model complexity precludes analytic solutions, we present numerical results calculated with a set of baseline parameters intended to represent a "typical small reef fish" (Table 1), motivated by our previous work on F. lapillum (e.g., Shima and Swearer 2010, Swearer and Shima 2010). The key characteristics are a maturation delay of $1 / \theta_{\mathrm{h}}=1$ year for a high-quality settler in the absence of competition (see Eqs. 5-6), and an average adult lifespan of $1 / \delta_{\mathrm{a}}=1$ year. We selected the remaining parameter values to maintain relatively low survival from settlement to maturation.

\section{Results}

We begin by considering the case in which all settlers are identical, then compare the results when settlers consist of both quality types. We arbitrarily take all settlers to be high quality $\left(p_{\mathrm{h}}=1\right)$ and use the parameter values in Table 1 to demonstrate the qualitative results over a range of settlement rates $(S)$. Increasing settlement rate initially leads to higher maturation rate and therefore greater equilibrium adult density; however, increasing the settlement rate further eventually causes the adult equilibrium to decline and asymptotically approach zero (Fig. 1a). This occurs because competition among juveniles lengthens the development delay (Fig. 1b), which allows greater mortality prior to maturation.

In contrast with previous models for space limited populations (e.g., Roughgarden et al. 1985, Bence and Nisbet 1989; see Appendix A) the equilibrium is stable at high as well as low values of settlement rate (Fig. 1). The stabilizing effect of high settlement is a result of the additional density dependence in the juvenile development rate (Eq. 5; see Appendix A). The existence of cycles depends on two key features: (1) high settlement rate that allows the juvenile population to overshoot the equilibrium before juveniles mature into adults that suppress further juvenile survival and (2) sufficiently high survival through the juvenile stage such that maturing juveniles overshoot the adult equilibrium. Because the maturation delay increases with settlement rate (due to competition among juveniles: Eqs. 5-6, Fig. 1b), total mortality during the juvenile stage also increases, which prevents the maturation rate from 
overshooting the equilibrium. The same qualitative pattern for the equilibrium and its stability occurs for homogeneous settlers with any value of maximum development rate between $\theta_{1}$ and $\theta_{\mathrm{h}}$ (see Appendix B).

Introduction of demographic heterogeneity $\left(0<p_{\mathrm{h}}<\right.$ 1) has profound effects on the population dynamics. Stability analysis shows that a mixture of the two types with $\theta_{\mathrm{l}}$ and $\theta_{\mathrm{h}}$ (Table 1 ) can result in a stable equilibrium for all values of settlement rate (Fig. 2a, e.g., a vertical slice at $p_{\mathrm{h}}=0.1$; see Appendix B). Note that if settlement consisted of either quality type alone $\left(p_{\mathrm{h}}=0\right.$ or $p_{\mathrm{h}}=1$, along left- or right-hand edge of Fig. 2a), the equilibrium would be unstable at intermediate settlement rates, as described above. (The stable region at low $S$ for extremely low or high $p_{\mathrm{h}}$ is difficult to see on the scale of Fig. 2, but the qualitative pattern at either extreme is identical to Fig. 1; see Appendix B.) Nevertheless, for settlement rates at which either type alone would result in an unstable equilibrium, a mixture of the two can give rise to a stable equilibrium (e.g., from $p_{\mathrm{h}} \approx 0.01$ to $p_{\mathrm{h}} \approx$ 0.11 ). This stabilizing effect of mixing quality types is not simply a result of the average development rate changing with $p_{\mathrm{h}}$ (i.e., $\theta_{\mathrm{avg}}=p_{\mathrm{h}} \theta_{\mathrm{h}}+\left(1-p_{\mathrm{h}}\right) \theta_{\mathrm{l}}$; Fig. $2 \mathrm{~b}$, see Appendix B); instead, it depends on the presence of both types among settlers. (In Appendix $\mathrm{C}$ we examine the influence of other parameters that might be affected by settler quality, i.e., $\alpha_{q}, b_{i j}, \delta_{\mathrm{j} q}$.)

Demographic heterogeneity stabilizes the dynamics by modifying the interaction between the maturation delay and juvenile mortality. Where settlement of only low-quality larvae would result in an unstable equilibrium at intermediate settlement rate (left edge of Fig. $2 a)$, the addition of some high-quality settlers allows some juveniles to mature quickly and (as adults) suppress further maturation that would overshoot the equilibrium. Similarly, intermediate settlement of only high-quality larvae would produce an unstable equilibrium (right edge of Fig. 2a), but the addition of enough low-quality settlers slows development below the rate at which maturation can overshoot the equilibrium. The mixture of development speeds effectively dampens the over/undershoot process that would otherwise lead to cyclic dynamics (see Appendix B: Fig. B8).

\section{DiscusSION}

Our model is a novel implementation of demographic heterogeneity in the theory of open population dynamics. We focused on the interaction between heterogeneity and density dependence in individual development rate, which is known to influence the stability properties of related models (Roughgarden et al. 1985, Bence and Nisbet 1989, Artzy-Randrup et al. 2007). Delayed density dependent feedback is generally destabilizing in population dynamics. Here, we showed that settlement of a mixture of quality types with different delays can ameliorate this destabilizing effect.
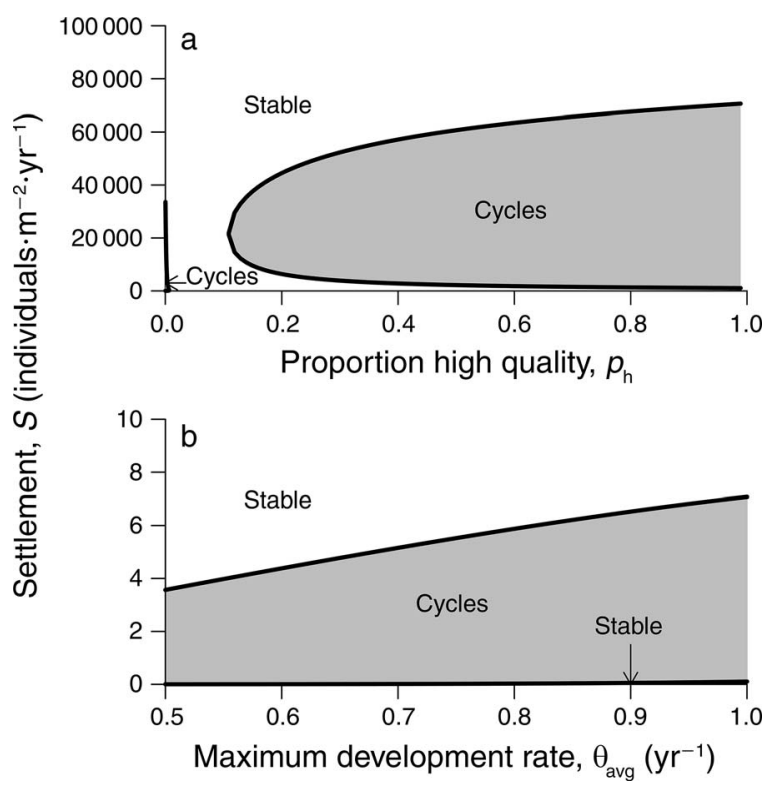

FIG. 2. Stability boundaries for (a) the model with demographic heterogeneity in maximum juvenile development rates $\left(\theta_{1}=0.5, \theta_{\mathrm{h}}=1\right)$, and (b) the model with homogeneous settlers with maximum development rate equal to the weighted average of low and high values in the heterogeneous case, i.e., $\theta_{\text {avg }}=p_{\mathrm{h}} \theta_{\mathrm{h}}+\left(1-p_{\mathrm{h}}\right) \theta_{\mathrm{l}}$ for values of $p_{\mathrm{h}}$ in panel a (see Table 1 for parameter definitions). The models predict an unstable point equilibrium with stable limit cycles for parameter values in the shaded regions, and a stable point equilibrium otherwise. Fig. 1 represents a vertical cross-section at $p_{\mathrm{h}}=1$, i.e., homogeneous settlers with maximum development rate $\theta_{\mathrm{h}}=1$. Similarly, a vertical cross-section at $p_{\mathrm{h}}=0$ corresponds to homogeneous settlers with $\theta_{\mathrm{l}}=0.5$. At both extremes of $p_{\mathrm{h}}$, the equilibrium is stable at low $S$, as in Fig. 1 (see Appendix B). For the model with homogeneous settlers (panel b), the equilibrium is stable at low $S$ for all values of $\theta_{\text {avg }}$ (this is difficult to see on the scale of this graph).

We adopted a relatively simple set of assumptions in the present study in order to maintain the link with earlier theory, but we expect additional model modifications will be useful for understanding particular natural systems. For example, a local population might receive settlers from several subpopulations, which, combined with variability in oceanographic conditions, could create a wide variety of quality types in the juvenile population. These types might correspond to more than two different values for one parameter (e.g., maximum development rate, $\theta_{q}$, as above), or simultaneous variation in multiple parameters.

Another source of variation that we ignored in our simulations is stochasticity in the environmental conditions that influence settlement rate. Recruitment in open marine populations is notoriously variable in both space and time (Caley et al. 1996, Doherty et al. 2004), and this may often produce what appear to be "boom-bust" dynamics within a subpopulation (Uthicke et al. 2009). If similar environmental conditions shape both the phenotypic quality of larvae and their probability of 


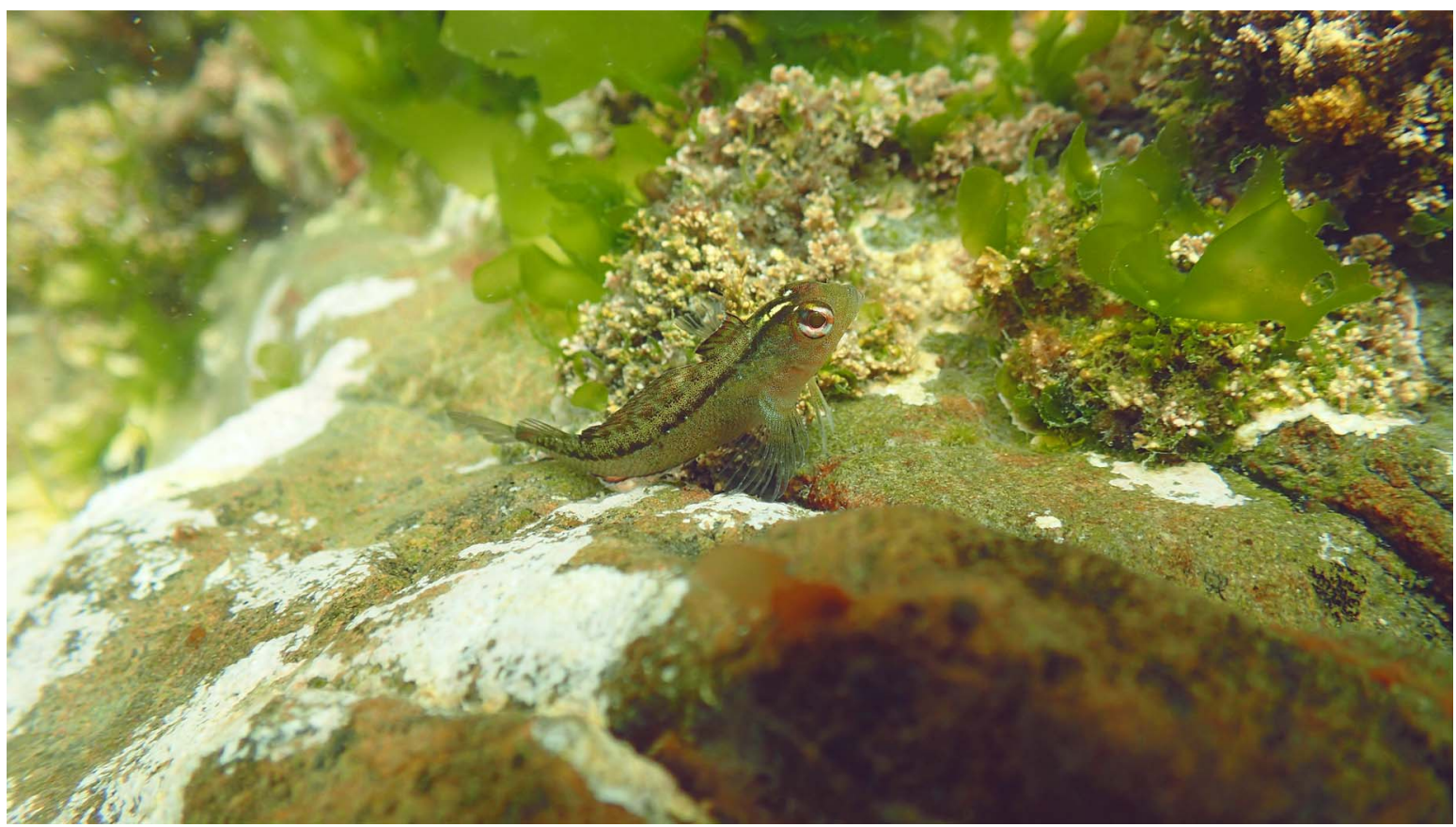

Plate 1. Common triplefin, Forsterygion lapillum, in Wellington Harbour, NewZealand. Photo credit: Becky Focht.

surviving to settlement stage (e.g., Cushing 1975, Lasker 1981), then high settlement events may be predominantly comprised of high-quality larvae and vice versa (see, e.g., Swearer et al. 1999, Wilson and Osenberg 2002, Shima and Osenberg 2003, Forrester and Steele 2004, Shima and Swearer 2009b, Swearer and Shima 2010, Zabel et al. 2011). Although our deterministic model predicts a stable equilibrium at either extreme of this continuum (corresponding to the top-right and the bottom-left quadrants of Fig. 2a), understanding the consequences of temporal variation between the extremes for density dependent interactions among settlers will require explicit treatment of stochasticity in future theoretical work.

The model framework that we developed considers only a single, demographically open subpopulation embedded in a larger metapopulation. Although experiments are typically feasible only at the subpopulation scale, the dynamics of entire metapopulations are clearly relevant to basic and applied ecological questions concerning population regulation and management. In real marine systems the local and global dynamics necessarily generate feedbacks, i.e., the (heterogeneous) larval pool that supplies settlers to one subpopulation is the reproductive output of a potentially large number of other more or less well-connected subpopulations. Our model results suggest that the impact of connectivity on population dynamics can go beyond the potential to rescue local populations that are in decline or to recolonize empty habitat patches after disturbances, as interactions between connectivity and local density dependent processes will influence stability at both local and regional scales.

\section{ACKNOWLEDGMENTS}

The authors thank the FAU Undergraduate Research Mentoring program (NSF-URM \#0829250) and an FAU Undergraduate Research Grant to A. Chen. The Royal Society of New Zealand Marsden Fund provided additional support for this project. The manuscript benefited from constructive criticism by Bruce Kendall and two anonymous reviewers.

\section{Literature Cited}

Armsworth, P. R. 2002. Recruitment limitation, population regulation, and larval connectivity in reef fish metapopulations. Ecology 83:1092-1104.

Artzy-Randrup, Y., R. Olinky, and L. Stone. 2007. Sizestructured demographic models of coral populations. Journal of Theoretical Biology 245:482-497.

Bence, J. R., and R. M. Nisbet. 1989. Space-limited recruitment in open systems: the importance of time delays. Ecology 70 : 1434-1441.

Burgess, S. C., and D. J. Marshall. 2011. Are numbers enough? Colonizer phenotype and abundance interact to affect population dynamics. Journal of Animal Ecology 80:681687.

Burgess, S. C., K. J. Nickols, C. D. Griesemer, L. A. K. Barnett, A. G. Dedrick, E. V. Satterthwaite, L. Yamane, S. G. Morgan, J. W. White, and L. W. Botsford. 2014. Beyond connectivity: how empirical methods can quantify population persistence to improve marine protected-area design. Ecological Applications 24:257-270.

Burgess, S. C., E. A. Treml, and D. J. Marshall. 2012. How do dispersal costs and habitat selection influence realized population connectivity? Ecology 93:1378-1387.

Caley, M. J., M. H. Carr, M. A. Hixon, T. P. Hughes, G. P. Jones, and B. A. Menge. 1996. Recruitment and the local dynamics of open marine populations. Annual Review of Ecology and Systematics 27:477-500. 
Cushing, D. H. 1975. Marine ecology and fisheries. Cambridge University Press, Cambridge, UK.

Doherty, P. J., V. Dufour, R. Galzin, M. A. Hixon, M. G. Meekan, and S. Planes. 2004. High mortality during settlement is a population bottleneck for a tropical surgeonfish. Ecology 85:2422-2428.

Forrester, G. E., and M. A. Steele. 2004. Predators, prey refuges, and the spatial scaling of density-dependent prey mortality. Ecology 85:1332-1342.

Gilarranz, L. J., and J. Bascompte. 2012. Spatial network structure and metapopulation persistence. Journal of Theoretical Biology 297:11-16.

Gurney, W. S. C., and R. M. Nisbet. 1998. Ecological dynamics. Oxford University Press, New York, New York, USA.

Hastings, A., and L. W. Botsford. 2006. Persistence of spatial populations depends on returning home. Proceedings of the National Academy of Sciences USA 103:6067-6072.

Hixon, M. A., T. W. Anderson, K. L. Buch, D. W. Johnson, J. B. McCleod, and C. S. Stallings. 2012. Density-dependence and population regulation in marine fish: a large-scale, longterm field manipulation. Ecological Monographs 82:467489.

Hixon, M. A., and G. P. Jones. 2005. Competition, predation, and density-dependent mortality in demersal marine fishes. Ecology 86:2847-2859.

Houde, E. D. 1989. Comparative growth, mortality, and energetics of marine fish larvae - temperature and implied latitudinal effects. Fishery Bulletin 87:471-495.

Inaba, H. 2002. Nonlinear dynamics of open marine population with space-limited recruitment: the case of mortality control. Journal of Mathematical Analysis and Applications 275:537556.

Kendall, B. E., G. A. Fox, M. Fujiwara, and T. M. Nogeire. 2011. Demographic heterogeneity, cohort selection, and population growth. Ecology 92:1985-1993.

Lasker, R. 1981. Marine fish larvae: morphology, ecology, and relation to fisheries. University of Washington Press, Seattle, Washington, USA.

Marshall, D. J., K. Monro, M. Bode, M. J. Keough, and S. Swearer. 2010. Phenotype-environment mismatches reduce connectivity in the sea. Ecology Letters 13:128-140.

McCormick, M. I., and A. S. Hoey. 2004. Larval growth history determines juvenile growth and survival in a tropical marine fish. Oikos 106:225-242.

Melbourne, B. A., and A. Hastings. 2008. Extinction risk depends strongly on factors contributing to stochasticity. Nature 454:100-103.

Nisbet, R. M., and J. R. Bence. 1989. Alternative dynamic regimes for canopy-forming kelp: a variant on density-vague population regulation. American Naturalist 134:377-408.

Pascual, M., and H. Caswell. 1991. The dynamics of a sizeclassified benthic population with reproductive subsidy. Theoretical Population Biology 39:129-147.
Pechenik, J. A., D. E. Wendt, and J. N. Jarrett. 1998. Metamorphosis is not a new beginning. BioScience 48:901910.

Pinsky, M. L., S. R. Palumbi, S. Andréfouët, and S. J. Purkis. 2012. Open and closed seascapes: where does habitat patchiness create populations with high fractions of selfrecruitment? Ecological Applications 22:1257-1267.

Roughgarden, J., S. Gaines, and H. Possingham. 1988. Recruitment dynamics in complex life cycles. Science 241: $1460-1466$.

Roughgarden, J., Y. Iwasa, and C. Baxter. 1985. Demographic theory for an open marine population with space-limited recruitment. Ecology 66:54-67.

Shima, J. S., and C. W. Osenberg. 2003. Cryptic density dependence: effects of spatio-temporal covariation between density and site quality in reef fish. Ecology 84:46-52.

Shima, J. S., and S. E. Swearer. 2009a. Larval quality is shaped by matrix effects: implications for connectivity in a marine metapopulation. Ecology 90:1255-1267.

Shima, J. S., and S. E. Swearer. 2009b. Spatially variable larval histories may shape recruitment rates of a temperate reef fish. Marine Ecology Progress Series 394:223-229.

Shima, J. S., and S. E. Swearer. 2010. The legacy of dispersal: larval experience shapes persistence later in the life of a reef fish. Journal of Animal Ecology 79:1308-1314.

Steele, M. A., and G. E. Forrester. 2002. Early postsettlement predation on three reef fishes: effects on spatial patterns of recruitment. Ecology 83:1076-1091.

Stover, J. P., B. E. Kendall, and G. A. Fox. 2011. Demographic heterogeneity impact density-dependent population dynamics. Theoretical Ecology 5:297-309.

Swearer, S. E., J. E. Caselle, D. W. Lea, and R. R. Warner. 1999. Larval retention and recruitment in an island population of a coral-reef fish. Nature 402:799-802.

Swearer, S. E., and J. S. Shima. 2010. Regional variation in larval retention and dispersal drives recruitment patterns in a temperate reef fish. Marine Ecology Progress Series 417:229236.

Uthicke, S., B. Schaffelke, and M. Byrne. 2009. A boom-bust phylum? Ecological and evolutionary consequences of density variations in echinoderms. Ecological Monographs 79:3-24.

Vigliola, L., and M. G. Meekan. 2002. Size at hatching and planktonic growth determine post-settlement survivorship of a coral reef fish. Oecologia 131:89-93.

White, J. W., and J. E. Caselle. 2008. Scale-dependent changes in the importance of larval supply and habitat to abundance of a reef fish. Ecology 89:1323-1333.

Wilson, J., and C. W. Osenberg. 2002. Experimental and observational patterns of density-dependent settlement and survival in the marine fish, Gobiosoma. Oecologia 130:205215.

Zabel, R. W., P. S. Levin, N. Tolimieri, and N. J. Mantua. 2011. Interactions between climate and population density in the episodic recruitment of bocaccio, Sebastes paucispinis, a Pacific rockfish. Fisheries Oceanography 20:294-304.

\section{Supplemental Material}

\section{Ecological Archives}

Appendices A-C are available online: http://dx.doi.org/10.1890/14-1531.1.sm 


\section{University Library}

\section{- M M I N E R VA A gateway to Melbourne's research publications}

Minerva Access is the Institutional Repository of The University of Melbourne

Author/s:

Noonburg, EG;Chen, A;Shima, JS;Swearer, SE

Title:

Demographic heterogeneity and the dynamics of open populations

Date:

2015-05-01

Citation:

Noonburg, E. G., Chen, A., Shima, J. S. \& Swearer, S. E. (2015). Demographic heterogeneity and the dynamics of open populations. ECOLOGY, 96 (5), pp.1159-1165. https:// doi.org/10.1890/14-1531.1.

Persistent Link:

http://hdl.handle.net/11343/116029 